Cuento 



\section{La mano izquierda de Dios}

\section{Carlos Calderón Fajardo}

El cuadro se lo atribuía como suyo una tal Anouk tan reticente como la mujer que había servido de modelo. Andrés Montero lo observó un buen rato y luego cerró el periódico.

Contempló turbado la inmensidad del cielo desde la ventanilla del avión. ¿No era más inmenso, más infinito que todos los cielos juntos dedicar una vida entera a pintar un solo retrato? Tancredo Luna, artista de una sola obra, había pintado ese único lienzo mientras vivió durante largos años una ahora evidente doble vida en París. Una mujer triste, pintada al óleo, según la breve apostilla periodística que acompañaba a la fotografía, el cuadro acababa de ser exhibido en una colectiva de arte latinoamericano en una galería de la rue Dragon por la que alguna vez Tancredo había ambulado sin adivinar el futuro.

Montero trató de recordar la cara de la mujer del retrato y pretendió comprender un propósito. Habían sido tantas las mujeres idolatradas por el zambo Tancredo; amante desdichado, bebedor insaciable, nocturno y enclaustrado. El pintor creía acumular existencias superponiendo retratos, uno quedaba debajo del otro. Trabajaba de madrugada. Tancredo no pintaba jamás de día sino a aquella hora que 
según su opinión le permitía atrapar en la luz mortecina y naciente el tono preciso para pintar la expresión de la mujer idealizada por el quebranto. ¿Era esa la explicación?

El avión en el que viajaba Montero hizo escala en la Martinica para abastecerse de lubricante. Y cuando el aparato era apenas un punto desplazándose a gran altitud sobre el Atlántico, sacó nuevamente el recorte de periódico que había guardado doblado en su cartera. En la penumbra adivinó lo que había existido a su lado sutilmente inadvertido. Cómo pensar en otra cosa que no sea en ese retrato que había irrumpido en su vida curiosamente coincidiendo con su regreso a París después de tantos años de ausencia. La inesperada Anouk, la plagiaria que se había apropiado de la única obra de su amigo Tancredo, por el nombre, porque Montero vio su último día en París a Anouk Aimée con sus grandes ojos que parecían mirar al cielo en un bistrot, horas antes de su despedida parisina. En la cena en casa del poeta Elqui Burgos, Montero había comentado el encuentro con Anouk Aimée. Pero no recordaba el chiste del siempre ocurrente Tancredo; ese día Andrés Montero había reído a carcajadas sin imaginar que nunca más vería a su amigo.

La triste noticia le llegaría un par de años después estando Montero ya reinstalado en Lima de manera definitiva: "Se murió el zambo" decía Elqui en su carta. Y muchos años después, cuando Andrés Montero cruzaba el cielo de vuelta a París como una pluma que cae en el vacío, estaba consciente de que lo esperaba un mundo irreconocible. Temía enfrentar lo que repetían con insistencia en sus cartas aquellos que decidieron permanecer en París. El mundo que conocieron había muerto, le decían. Y en el avión, Montero intentó revivir un trozo de música, un gesto, una palabra dicha por alguien, un atisbo; la punta de un hilo de donde jalar hasta dar con la verdadera identidad de la mujer cuyo rostro había obsesionado a Tancredo al punto de pintarlo mil veces. Recordó la buhardilla de Elqui en el séptimo piso de un inmueble cenizo en la avenida Georges Mandel y la puerta verde del cubículo donde vivían dos fieras, un par de sirvientas portuguesas provenientes de una minúscula aldea cerca a Coimbra, y el taller de Tancredo una puerta más allá.

El día de la despedida de Andrés Montero, el que se iba de París ya estaba ligeramente ebrio cuando empezaron a llegar los invitados. 
Armando, que no bebía, se apareció temprano trayendo una botella de beaujolais; Armando en esa época se encontraba empeñadísimo en conseguir sonoras resonancias en castellano de poemas de Benjamin Peret considerados como parte de una obra secreta.

Luego de cenar, como siempre el zambo Tancredo alzó la gran envergadura de sus noventa kilos y llamó insinuante con el dedo índice a sus amigos, a Armando y a Montero, para invitarlos a visitar su taller.

-Quiero mostrarles mi último cuadro-les dijo.

Montero intercambió una mirada sonriente y cómplice, con Armando. ¿El último cuadro? Siempre era un acontecimiento muy especial echarle un vistazo a la última obra de Tancredo, mejor dicho a un mismo cuadro insistentemente renovado, retocado infinidad de veces. Tancredo añadía en cada oportunidad un nuevo detalle. Inacabable el número de enmendaduras. Tenía de alguna manera razón Tancredo Luna: un cuadro con una pincelada adicional encima era ya otro cuadro.

El lienzo en el que el artista había volcado toda una vida dormía en su caballete tapado con una camisa y eso lo recordaba perfectamente Montero.

Muchas veces esa obra única había sido motivo de comentarios en broma y en serio por parte de los amigos, sobre todo de los que se consideraban artistas viviendo en París. Elqui trabajaba cual orfebre precavido en un mismo poemario, día a día, mejor dicho año a año y hacía demasiado tiempo que no publicaba. Armando, más intenso en cuanto a su producción poética, sucesivas veces les había confesado a sus amigos su aspiración de no escribir otra cosa que no sea un mismo poema hasta que escribir se convierta en el esfuerzo de lo que jamás concluye. Armando sabía lo que le iba a pasar debido a una maligna dolencia que se cuidó en ocultar. Recordando ese momento en el taller de Tancredo, Montero comprendió lo que el pintor pretendió comunicar: que la vida puede justificarse repitiendo, en el acto constante y obsesivo de pulir; el secreto de cualquier actividad humana estaba en el retoque.

Ya en su taller, es decir en aquella buhardilla tapiada y de escasa luz, con muros porosos donde estamparon sus versos los amigos furtivos, los retenidos en el destierro, Tancredo mostró su colección de fotos en blanco y negro de deslumbrantes artistas de cine, aquellos 
rostros de ojos tentadores de los cuales el pintor extraía la sombra y el matiz. En el centro de la buharda una mesa sobrecargada de cartulinas, crayolas, resinas y tintas; allí Tancredo desnudaba la legendaria tela. La sonrisa aviesa de una mujer de pequeña estatura, de mediana edad, engullida en un tono rosa muy tenue casi blanco. ¿Era el mismo cuadro que una tal Anouk firmaba como suyo años después? Montero dudó sin comprender por qué.

Cuando Tancredo pintaba con obcecación ese lienzo, Armando no había muerto aún, tampoco Julio Ramón, ni Tancredo, que encarnaba la vida vivida con toda la pasión que era posible en un ser humano; tampoco él había abandonado aún este mundo. Ninguna ilusión había fenecido todavía. El avión en el que Montero cruzó los cielos rumbo a ese mundo irrecuperable por fin se posó suavemente sobre la pista del recientemente inaugurado aeropuerto Charles de Gaulle.

Se hospedó en el viejo hotel Excelsior, en la rue Cujas. Se sentó en el lobby. Encendió un cigarrillo y paseó su mirada por el vestíbulo. Las alfombras eran las mismas, con dibujos orientales. Entre los huéspedes no había franceses, más bien árabes y vietnamitas. Las cortinas de tafetán tapaban una ventana cuyos batientes daban sobre un cabaret frecuentado por asiáticos.

Salió a la acera. De inmediato se percató de la presencia de una especie de luz desconocida que se posaba sobre las cosas. Era un día de principios de junio. Casi a las seis de la tarde el aire recorría aún cálido y esa luz oblicua estaba allí, aún brillante. Qué había pasado exactamente un día como ese casi treinta años atrás. A Montero se le ocurrió que hubo otro tipo de luz. Tancredo le había enseñado en esa época a beber un aperitivo de noche. Compró el diario Le Monde en un kiosco. Fue un gesto mecánico. Dobló el periódico y lo colocó bajo su brazo. No le interesaba leerlo, sin embargo se sentó en la terraza de un café. Pidió un Pernod y se puso a leer el periódico. Le parecía más angosto el bulevar, más oscura una librería que le fue familiar. Alguien en una mesa cercana a la suya leía un libro de Paul Nizam. "Estoy de vuelta -se dijo Montero-, acá de nuevo. Conseguí volver. Aún estoy vivo".

Le daba cierto resquemor hablar en francés, como si fuera a equivocarse al escoger las palabras correctas. 
Por el bulevar pasaban muchos norteamericanos en zapatillas y japoneses con gorra de tela, siempre habían frecuentado esa zona de París, pero ésos parecían distintos, distraídos, aburridos. Montero pidió un segundo Pernod. Continuó hojeando el periódico. No era un turista, sino alguien que ha llegado a esa ciudad con una consigna.

Y la noche fue ingresando poco a poco. Años atrás al prenderse las luces en las farolas, Montero se habría parado de esa mesa y pleno de ilusión se habría dirigido a Montparnasse, pero ahora sabía, con más de cincuenta años encima, que no tenía tiempo; había perdido mucho pelo; la mala circulación le ocasionaba cierta pesantez en las piernas; claro que seguía midiendo un metro ochenta pero ahora se movía con lentitud. Montero seguía siendo un hombre de espaldas anchas, pero ahora se sabía muy vulnerable, y se había tornado medroso. Le temía a la noche. Dejó el periódico en la mesa. Sólo deseaba regresar al hotel y meterse en la cama. Echado en la cama podía ver los nuevos programas de la televisión francesa y otros canales europeos.

-Te has vuelto un cobarde -dijo Tancredo, con ese timbre de voz que Montero reconoció de inmediato. Ésa fue la primera vez que Tancredo se le aproximó indeciso como parte de esa incomprensible luz que Montero creía ver impregnando las superficies.

Antes de acostarse, luego de ubicar su maleta en un placard, se comunicó por teléfono con Elqui.

Al día siguiente, después de desayunar en un McDonald's de la rue Monsieur Le Prince se dispuso a caminar por París. Después de ambular sin rumbo toda la mañana por calles que redescubría terminó almorzando en un antiguo restaurante con mantel a cuadros en el bulevar de Gobelinos. Él mismo se sorprendía de no desear verlo todo como si fuese la última vez.

En ese su segundo día en París sentía que tenía que realizar una serie de actos aparentemente gratuitos pero concatenados, actos que debían enlazarse.

Elqui había quedado en verse con Montero al final de la tarde de ese día.

Después de almorzar se sentó en un bistrot que hacía esquina en una calle de afligidos. Los taburetes desvencijados y sucios. En un ángulo 
atenebrado un hombre estaba allí para decir que se parecía a Tancredo; probablemente un somalí viejo con el pelo bastante crecido y una corta barba gris y babuchas orientales en los largos pies resecos. Montero pensó que si Tancredo estuviese aún vivo sería como ese viejo africano.

Andrés Montero percibió el rostro de ese hombre bajo un reflejo amarillento. Cómo evitar esa sonrisa bellaca, terrible. Terminó su cerveza y salió disimulando su inquietud, lentamente buscando la luz. A sus espaldas Montero intuyó la inconfundible, burlona, risa de Tancredo.

Volvió a llamar por teléfono.

Elqui y Melida con el tiempo habían mejorado sus condiciones de vida en París y vivían en un ventilado y bastante confortable departamento en un barrio obrero de los suburbios.

"En la plaza del Odeón", había dicho Elqui por teléfono y no hubo necesidad de decir más. En el café La Bombonniere, en esa mesa, en la terraza; tras una mampara humedecida intermitentemente por la lluvia se avistaba la estatua de Danton picada por el verdín de la herrumbre. Elqui asomó sonriente. Eran muchos los años que Montero no lo veía y ni una sola cana asomaba en la cabellera negra y ondulada del amigo tierno; su manera de hablar no había variado de cuando era un silencioso niño en un colegio de Cajamarca, con modulación pausada como suspendiendo las palabras.

-Melida nos espera a almorzar -dijo.

Camino a la ahora su nueva casa, Elqui le fue informando a Montero sin dramatizar sobre los que consideraba contundentes cambios producidos en la ciudad. Como siempre en París nada había cambiado y la vida era sin embargo otra. Había fallecido de un síncope en plena ejecución de su instrumento, en plena noche, el viejo arpista venezolano del bar Mónaco. Elqui se explayaba sobre diversos temas y Montero reparó que eludía referirse a Tancredo Luna.

Melida había cuidado su antigua inocencia. Con el pelo suspendido en forma de rodete tras la nuca se mantenía fiel a los pantalones bluyín y a la chompa enrollada en el cuello. Sólo sus manos de dedos cortos y delgados lucían algo cuarteadas. 
Ya en su casa, mientras consumían la botella de pisco que había volado con Montero desde el Perú, recordaron, como era de usanza, las sabrosas anécdotas vividas años atrás.

Tocaron a la puerta.

-¡Anouk! -exclamó Elqui. La pintora ingresó a la casa de los Burgos con el desparpajo de un saltamontes en verano. Montero, perplejo, notó que esa mujer aún joven le recordaba a la Anouk Aimée que había visto el día de su despedida con un abrigo de cuero de camello y con botas altas; erguida como una zacuara ondulante, francesa, llamaba la atención de Montero la piel de Anouk de un tono bastante oscuro y sus cejas pobladas. Elqui y Melida la trataban con trabajada intimidad, con confianza. Montero reparó que la miraban con ternura. En cambio él no podía disimular su desconcierto. La mujer del cuadro de Tancredo estaba delante suyo, con espléndida frescura y lo observaba con suspicacia.

El almuerzo se desarrolló en una atmósfera de intimidad.

En la primera oportunidad en que Anouk y Montero se quedaron solos él le dijo en tono imprecativo:

-Un cuadro que usted dice que es suyo pertenece al pintor Tancredo Luna.

-Tancredo Luna es mi padre -respondió imperturbable Anouk.

Fue cierto matiz en la voz, o quizás una inocultable inquietud en la mirada, o posiblemente la súbita revelación de saber de quién era hija, la verdad es que en ese momento Andrés Montero se sintió perturbado por la presencia de un ser que alguna vez había existido inadvertido, cerca, a su alrededor y que pertenecía a la vida secreta de Tancredo Luna.

Montero continuó buscando detalles en el rostro de Anouk durante el almuerzo. No le hallaba parecido físico con su padre; aunque Montero tuvo que reconocer que había heredado el unívoco humor de Tancredo.

- ¿Te has dado cuenta de quién es? -preguntó misteriosa Melida a la hora del postre, señalando a Anouk.

-No, no sé -respondió Montero ruborizándose, mintiendo. 
-Es Anouk Luna, hija de Tancredo -terció Elqui con ese cierto desdén que se utiliza al proporcionar una revelación.

Luego de una conversación de sobremesa que se prolongó durante casi toda la tarde, Anouk se ofreció a llevar a Montero en su auto de regreso a París. Cuando ya en el auto Montero le pidió que le explicara por qué firmaba el cuadro de su padre, ella contestó:

-Que yo lo exhiba como mío tiene que ver con el secreto oculto en la pintura de Tancredo Luna.

Sin consultarle su opinión, en lugar de llevar a Montero al hotel donde él se había alojado, Anouk condujo su auto rumbo al Trocadero.

En la avenida Georges Mandel, en silencio bajaron del auto. Mientras subían los ahora para Montero interminables ocho pisos del edificio, Montero le confió a Anouk que no había podido conciliar el sueño desde que había llegado a París. Se sentía muy emocionado pero no deseaba delatar sus sentimientos. Se dirigían al taller de Tancredo.

Nada había cambiado aparentemente, aunque fuese otra la gente viviendo temporalmente en esas buhardillas; ya no vivía ni un solo poeta peruano allí, ni tampoco las dos inquietas portuguesas conversonas. Anouk había heredado el taller de su padre.

-No puedo pintar en otro sitio -dijo ella.

Sacando las llaves de su cartera, abrió la puerta. Montero se sintió invadido por las reminiscencias al sentir el olor a pintura fresca y a disolvente. El cuarto se conservaba exactamente como lo había dejado Tancredo. Anouk había heredado la utilería completa: maquetas, atriles, pinceles, e incluso el desorden. A Montero inmediatamente le llamó la atención una serie de cartulinas, de bosquejos que colgaban adosados de una pita como secando; configuraban una serie. Anouk, con más dominio técnico que Tancredo, había conseguido profundizar en el famoso cuadro de su padre hasta descomponerlo en sus más insignificantes detalles. Los bosquejos representaban madonas incompletas e inquietas. Cómo no se le había ocurrido antes, pensó Montero: la mujer que pintaba una y mil veces Tancredo era una madona. Por supuesto que él no las llamaba así, su fama de zambo travieso no se lo permitía. No eran mujeres de carne y hueso sino vírgenes imaginadas las que pintaba. 
-¡Las madonas de Tancredo! -exclamó Montero.

Anouk se sonrió. Asintió.

-He pintado toda la serie y las voy a exhibir este año en varias capitales europeas. Mi exposición la voy a llamar: "Las Madonas de Tancredo Luna". Yo continuo las búsquedas de mi padre.

-¿Qué búsquedas? -preguntó Montero desconcertado.

-Que el cuadro que pintaba mi padre quedó inconcluso y yo tengo la obligación de concluirlo. No el cuadro sino la idea que está contenida en él.

-¿Por qué pintaba siempre el mismo cuadro? -preguntó Montero esperando que la hija le responda lo que no quiso responder el padre.

-No era el mismo. Cuando alguien conoce y ama a una persona ve en ella todas sus expresiones que son muchas, es difícil escoger una. Mi padre decidió pintarlas todas.

Un rato después, Anouk le dio a entender a Montero que el secreto de la pintura de Tancredo Luna era como el mecanismo de las cajas chinas, constaba de varios compartimientos; un enigma con intercomunicadas cavidades ocultas. Anouk le preguntó a Montero si quería llegar hasta el final, si le interesaba conocer toda la verdad. Montero sonrió. Anouk lo cogió del brazo y sacándolo del taller prácticamente lo arrastró como quien manipula a un tío bueno por las escaleras hasta su carro.

Unos minutos después Anouk manejaba con pericia su carrito a gran velocidad por uno de los grandes bulevares de París. Montero tuvo la ocasión de observarla de cerca. Ya no le cupo la menor duda: la madre de Anouk había sido la modelo de un pintor enamorado.

Llegaron casi de noche a la plaza Maubert. Anouk se cuidó de no decirle con exactitud por qué lo había llevado a ese lugar, hasta la puerta de una iglesia en la rue Monge.

-Mañana temprano te espero aquí -dijo ella.

Esa noche Montero tampoco pudo dormir. Le zumbaban los oídos. El zambo Tancredo se paseaba como un desesperado por su mente. Lo recordó peleando en la plaza Clichy con un árabe que al 
verse perdido sacó un cuchillo. Lo vio como si fuese ayer pintando una pared amarilla, ganándose la vida como pintor de brocha gorda. Tancredo se cayó del andamio. Se le astilló un vidrio en sus anteojos. La luna astillada parecía una telaraña adherida. Con esos anteojos Tancredo asistía a los vernissages y a sus bares preferidos. Apareció espectral con ese terrible anteojo astillado y le pidió a Montero que no faltara a la cita con su hija.

Montero esta vez tomó desayuno en la plaza Maubert. Cerca del lugar donde debía encontrarse con Anouk, ocupó una mesa con vista a la calle, en un bistrot con aspecto de snack americano. Verduleros vietnamitas largos y flacos, en camisetas blancas caladas abrían las puertas metálicas de sus tiendas. Montero se puso a observar a uno de los asiáticos famélicos, de hombros puntudos, un cigarrillo colgaba tempranero de su labio azul. Alguien llegó a la tienda, un zambo encorvado. Montero creyó ver a Tancredo husmeando madrugador en esas pulperías. A cada instante que transcurría para Montero era como si lo que le estaba por ocurrir sobrevendría para satisfacer la curiosidad de conocer cómo va a terminar un sueño. Al margen del tiempo, Montero contemplaba las cosas como vistas desde afuera. Oyó la voz de Tancredo como un rumor leve, como un suspiro en su oreja, como si le hablara desde cenizas dormidas. Montero se sentía, por haber sobrevivido, como profanando ese París que existía al otro lado de un espacio insalvable desde donde era observado con misericordia.

Montero se sentía enfermo. Cada vez le zumbaban más los oídos. Todo lo que le había acaecido desde que bajó del avión en realidad se vinculaba con esa misma debilidad. El abandono, el agobio, la mortificación del sobreviviente; una especie de disgusto sin piedad por sí mismo; una luz diferenciada. Montero comprendió la verdad de esa luz para él siempre negada, huidiza; entendió que nunca accedería a lo que existe delante y que no es permitido ver.

El resto de la mañana, Montero caminó por las orillas del Sena sin alejarse mucho del lugar de su cita. Y convencido de que todo obedecía a un propósito, sin embargo sentía como si París se fuese apagando. El asombro de Montero se había ido debilitando; era consciente que la verdad le sería finalmente negada, que algo imprevisto le ocultaría el fondo de lo que no se volverá a repetir. 
Al mediodía, con botas altas y apoyada en su auto, Anouk lo esperaba en la puerta de la iglesia de Saint Nicolas de Chardonet.

Anouk parecía ser lo único real, aquello que une todas las partes. Su padre solía esfumarse como un diablo alucinado, por lo general de madrugada; abandonaba los bares del barrio del Marais diciendo que se iba a pintar. A veces se ausentaba por largas temporadas y al volver decía que había estado pintando en Amiens. Recién, tantos años después, Montero creía saber qué llenaba aquellos huecos negros, esos espacios vacíos a los que nunca Tancredo permitió acceder a nadie.

Anouk lo invitó a entrar en el templo.

El asombro se había tornado en fastidio. A Montero le dolía la cabeza; no entendía de qué manera el secreto de la pintura del zambo Tancredo pudiese ser develado dentro de una iglesia. "La modelo es una madona que está allí", era lo único lógico que se le ocurría.

Empezaron a caminar por la penumbra de una de las alas del templo. Montero levantaba la cabeza contemplando los arbotantes en el techo.

-¿No notas nada extraño? -preguntó, de pronto, Anouk.

Ella se lo preguntó parada delante de un altar.

-Mira bien -dijo, señalando a uno de los santos-, los santos franceses son incoloros. Si recuerdas a los santos en las iglesias de tu país los recordarás coloreados.

A Montero empezó a latirle fuertemente el corazón. Se le erizaba la piel por el sorpresivo giro que tomaba el secreto de la pintura de Tancredo Luna.

-Quiero mostrarte algo más -añadió Anouk.

Siguieron caminando por la iglesia. Anouk se detuvo.

-Mira ahora hacia allá, en esa pared -pidió señalando un espacio alto.

Montero dirigió su vista hacia el lugar donde ella indicaba. Allí colgaba un cuadro, desteñido a simple vista.

-Es un Corot-dijo Anouk, y enseguida añadió:-No es cierto que un pintor sin color sea un pintor falso, un pintor que lo dice todo con 
un color que casi no lo es, es un artista extraordinario. El misterio de la pintura aparentemente sin colores de Corot fue lo que retuvo a mi padre tantos años en París -terminó sentenciando Anouk.

Mientras salía de la iglesia dentro de Montero bullía una pregunta:

"¿Sólo eso lo retuvo?". Quiso preguntar, pero se contuvo. Era como insistir sobre algo innecesario.

-¿Ese es el secreto? -preguntó al final por preguntar.

Anouk se sonrió. Caminó hacia la puerta del templo. Al acercarse a la puerta el luminoso brillo que provenía del exterior hizo que Montero evocara los colores del mundo.

Fue una luz casi blanca. Dios extendió su mano izquierda y repitió el mismo retrato que pintaba siempre: Montero murió.

Luego Anouk desapareció en aquel fuego sin luz que es la sombra. 